\title{
ALUMINIUM OR CAST IRON?
}

Dear Reader,

The past few decades have seen a distinct trend towards aluminium cylinder blocks for passenger car engines. Initially used for gasoline engines, the material soon also became established in diesel engines. Experts estimate that more than half of all cylinder blocks for passenger car engines are currently made of aluminium. As the cylinder block accounts for up to $25 \%$ of the weight of a typical engine, great potential is offered by lightweight design.

Until recently, therefore, the rule was that any manufacturer who wanted to market a state-of-the-art car engine had basically no alternative than to use aluminium or the even lighter metal magnesium. But that may soon change, as increasing numbers of highly downsized engines are developed. The weight disadvantage of cast iron compared to aluminium is dependent on the cubic capacity and dimensions of the engine, and the difference in weight is less significant in small engines. For example, Ford makes the cylinder block for its highly acclaimed 1.01 three-cylinder EcoBoost engine out of cast iron. The manufacturer claims that it allows the engine to be made extremely compact. It dispenses with the need for balancer shafts, which even enables Ford to reduce the weight of the overall engine through this choice of material.

And this clearly applies not only to three-cylinder units. Opel is also equipping one of the engines that is vitally important for its future, the recently unveiled 1.61 four-cylinder gasoline engine, with a cast iron cylinder block combined with an aluminium bedplate. The car maker similarly argues that this downsized power unit offers a more compact design and better NVH properties due to its cast iron structure. It remains to be seen whether there will be a general trend back to cast iron. After all, there are still many good reasons in favour of aluminium, as Opel demonstrates elsewhere: for its new 1.61 diesel engine, aluminium is used for the cylinder block instead of cast iron - for the first time, by the way, in diesel engine production at Opel. This enabled Opel to achieve its own objective of setting the class benchmark for power-to-weight ratio. As is so often the case in engineering design, there seems to be no "one size fits all" solution. Instead, it is a question of how to best fulfil the requirements.

Best regards,

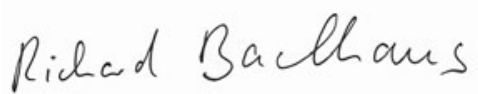

RICHARD BACKHAUS, Vice-Editor in Chief Wiesbaden, 13 April 2013

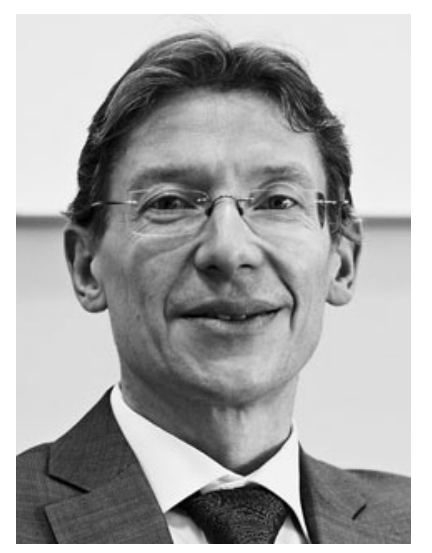

